\title{
Paradoxical Effects of Pyrazinoate and Nicotinate on Urate Transport in Dog Renal Microvillus Membranes
}

\author{
Sandra E. Guggino and Peter S. Aronson \\ Departments of Medicine and Physiology, Yale University School of Medicine, New Haven, Connecticut 06510
}

\begin{abstract}
The effects of pyrazinoate and nicotinate on urate transport in microvillus membrane vesicles isolated from canine renal cortex were evaluated. An outwardly directed gradient of pyrazinoate stimulated uphill urate accumulation, suggesting urate-pyrazinoate exchange. An inside-alkaline pH gradient stimulated uphill pyrazinoate accumulation, which suggested pyrazinoate$\mathrm{OH}^{-}$exchange. Pyrazinoate- $\mathrm{OH}^{-}$exchange and urate- $\mathrm{OH}^{-}$ exchange were similarly sensitive to inhibitors, implying that both processes occur via the same transport system. In addition, an inward $\mathrm{Na}^{+}$gradient stimulated uphill pyrazinoate accumulation, suggesting $\mathrm{Na}^{+}$-pyrazinoate cotransport. Inhibitor studies demonstrated that $\mathrm{Na}^{+}$-pyrazinoate cotransport takes place via the same pathway that mediates $\mathrm{Na}^{+}$-lactate cotransport in these membrane vesicles. Previously we found that urate does not share this $\mathrm{Na}^{+}$-dependent cotransport pathway. Nicotinate inhibited transport of pyrazinoate by the anion exchange pathway and the $\mathrm{Na}^{+}$cotransport pathway, suggesting that it is a substrate for both transport systems. Finally, in the presence of an inward $\mathrm{Na}^{+}$gradient, low doses of pyrazinoate or nicotinate stimulated urate uptake, and higher doses of pyrazinoate or nicotinate inhibited urate accumulation, thereby mimicking in vitro the paradoxical effects of drugs on renal urate excretion that have been observed in vivo. These findings indicate that the paradoxical effect of uricosuric drugs at low doses to cause urate retention may result at least in part from stimulation of urate reabsorption across the luminal membrane of the proximal tubular cell.
\end{abstract}

\section{Introduction}

Pyrazinoate, a metabolite of the antituberculous drug pyrazinamide, suppresses the renal excretion of urate $(1,2)$. This effect has been attributed to inhibition of the secretory component of bidirectional urate transport in the proximal tubule and forms the basis for the pyrazinamide suppression test in man (3). When given in higher doses, pyrazinoate actually enhances urate excretion $(2,4)$. Several other substances, such as salicylate, also have the paradoxical property of inhibiting urate excretion when administered in low doses and of stimulating urate excretion when given in high doses (5).

A summary of this work was published as an abstract in 1983 (Kidney Int. 23:256).

Address correspondence and reprint requests to Dr. Aronson, Department of Physiology.

Received for publication 10 December 1984 and in revised form 5 March 1985.

J. Clin. Invest.

(c) The American Society for Clinical Investigation, Inc.

0021-9738/85/08/0543/05 $\$ 1.00$

Volume 76, August 1985, 543-547
Previous work has identified a probenecid-sensitive anion exchanger that can account for uphill urate reabsorption across the luminal (microvillus, brush border) membrane of the proximal tubular cell of dog and rat (6-9). This transport system mediates the exchange of urate for any of several anions for which a cell-to-lumen electrochemical gradient is present across the luminal membrane. The known substrates for exchange with urate via this pathway are $\mathrm{OH}^{-}, \mathrm{Cl}^{-}, p-$ aminohippurate (PAH), ${ }^{1}$ several monocarboxylic acid anions (i.e., valerate, lactate, beta-hydroxybutyrate, pyruvate, and acetoacetate), the monovalent forms of certain dicarboxylic acid anions (i.e., maleate, succinate, alpha-ketoglutarate, and oxaloacetate), and the tricarboxylic acid anion cis-aconitate $(6-8)$.

We now report that pyrazinoate and nicotinate, another substance that causes urate retention (10), are substrates for the dog renal microvillus membrane anion exchange pathway shared by urate. Moreover, pyrazinoate and nicotinate are also substrates for an organic anion- $\mathrm{Na}^{+}$cotransport pathway not shared by urate. We demonstrate an interaction between these two luminal membrane transport systems in vitro that can explain the paradoxical effects of pyrazinoate and other compounds on urate excretion in vivo.

\section{Methods}

Membrane preparation. Microvillus membrane vesicles were isolated from mongrel dog renal cortex by the $\mathrm{Mg}^{++}$aggregation method previously described (6). In general, the membranes were prepared and suspended (25-30 mg membrane protein $/ \mathrm{ml}$ ) in a medium of 200 $\mathrm{mM}$ mannitol, $10 \mathrm{mM} \mathrm{MgSO}$, and $80 \mathrm{mM}$ Hepes titrated to $\mathrm{pH} 7.5$ with $41 \mathrm{mM} \mathrm{KOH} \mathrm{(8).} \mathrm{Membrane} \mathrm{vesicles} \mathrm{were} \mathrm{frozen} \mathrm{and} \mathrm{stored} \mathrm{at}$ $-70^{\circ} \mathrm{C}$ until used $(7,8)$.

Solute uptake studies. Uptake of radiolabeled solutes was assayed at $20^{\circ} \mathrm{C}$ by the rapid filtration technique previously described (11), using a stopping and washing solution of $170 \mathrm{mM}$ Na gluconate, 2 $\mathrm{mM} \mathrm{K}$ probenecid, $2.5 \mathrm{mM}$ Tris, and $4 \mathrm{mM}$ Hepes, pH 7.5 (8). Each experiment was performed in triplicate on at least three separate occasions, each time using a different membrane preparation. For experiments with $\mathrm{pH}$ and voltage clamps (see below), it was necessary to maintain the intravesicular and extravesicular $\mathrm{K}^{+}$concentrations approximately equal. Thus, the combination of $\mathrm{KH}_{2} \mathrm{PO}_{4}$ and $\mathrm{K}_{2} \mathrm{HPO}_{4}$ that would give the desired $\mathrm{pH}$ with the desired total $\mathrm{K}^{+}$concentration was empirically determined for each experimental solution. Additional details of the experimental methods are given in the figure legends. Unless stated otherwise, the figures illustrate absolute uptake values from single representative experiments.

Voltage and pH clamps. In one of the experiments to be described, the effect on urate uptake of imposing an outward gradient of pyrazinoate was evaluated to test for direct coupling of pyrazinoate efflux to urate influx. This strategy necessarily required that the direct effect of the pyrazinoate gradient be distinguished from indirect effects of the pyrazinoate gradient to generate transmembrane diffusion potentials or $\mathrm{pH}$ gradients. In dog renal microvillus membrane vesicles, at least

1. Abbreviation used in this paper: PAH, p-aminohippurate. 
a small component of urate uptake may be sensitive to alterations in the transmembrane electrical potential difference (7), and urate uptake is markedly affected by variations in the transmembrane $\mathrm{pH}$ gradient $(6,8)$. Accordingly, the effect of the pyrazinoate gradient was evaluated by using vesicles with equal internal and external $\mathrm{K}^{+}$concentrations in the presence of the $\mathrm{K}^{+}$ionophore valinomycin $(3 \mathrm{mg} / \mathrm{ml})$ to shortcircuit anion diffusion potentials (voltage clamp) and in the presence of the $\mathrm{K}^{+}-\mathrm{H}^{+}$exchanger nigericin $(150 \mu \mathrm{g} / \mathrm{ml})$ to collapse $\mathrm{pH}$ gradients (pH clamp). In other experiments, the effects of outward $\mathrm{OH}^{-}$gradients on organic anion uptake were evaluated. These experiments were performed in the presence of the $\mathrm{K}^{+}$-valinomycin voltage clamp to short-circuit $\mathrm{H}^{+} / \mathrm{OH}^{-}$diffusion potentials. The efficacy of the valinomycin voltage clamp and the nigericin $\mathrm{pH}$ clamp in these membranes has been demonstrated previously (8).

Materials. $\left[2-{ }^{14} \mathrm{C}\right]$ Urate $(61 \mathrm{mCi} / \mathrm{mmol})$ was obtained from Amersham Corp., Arlington Heights, IL; $\left[{ }^{14} \mathrm{C}\right] \mathrm{L}$-lactate $(165 \mathrm{mCi} / \mathrm{mmol})$ and $\left[{ }^{3} \mathrm{H}\right]$-D-glucose $(30 \mathrm{Ci} / \mathrm{mmol})$ from New England Nuclear, Boston, MA; probenecid and valinomycin from Sigma Chemical Co., St. Louis, MO; and nigericin from Eli Lilly \& Co., Indianapolis, IN. $\left[{ }^{14} \mathrm{C}\right]$ Pyrazinoate $(62 \mathrm{mCi} / \mathrm{mmol})$ and unlabeled pyrazinoate were the generous gifts of Dr. I. M. Weiner, Department of Pharmacology, SUNY Upstate Medical Center, Syracuse, New York.

\section{Results}

Our initial method to test the hypothesis that pyrazinoate shares the urate exchange pathway was to determine whether pyrazinoate would exchange with urate. As shown in Fig. 1, the uptake of $7 \mu \mathrm{M}\left[{ }^{14} \mathrm{C}\right]$ urate was assayed in the absence or presence of an outward gradient $(10 \mathrm{mM}$ inside, $0.2 \mathrm{mM}$ outside) of pyrazinoate. The experiment was conducted by using media of $\mathrm{pH} 6.5$ in the presence of both a valinomyin voltage clamp and a nigericin $\mathrm{pH}$ clamp. The outward gradient of pyrazinoate accelerated the rate of urate uptake and caused the transient accumulation of urate (overshoot) above equilibrium. In two other similar experiments not illustrated, the 2min accumulation of urate was 3.1- and 4.0-fold higher than the equilibrium level of urate uptake. These findings indicate that the outward movement of pyrazinoate must be directly

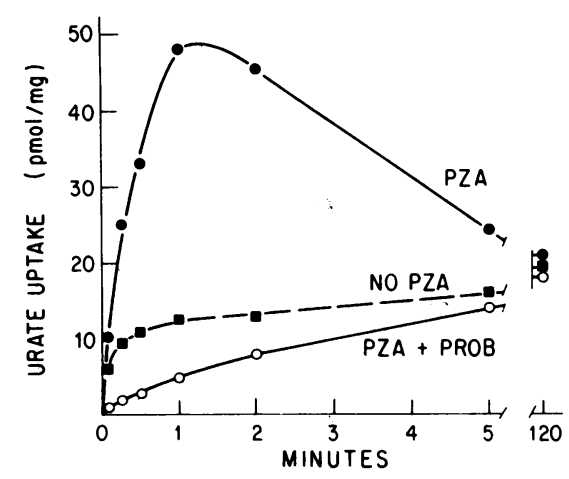

Figure 1. Stimulation of urate uptake by an outward pyrazinoate gradient. Membrane vesicles were preincubated for $120 \mathrm{~min}$ at $20^{\circ} \mathrm{C}$ in the presence of $150 \mu \mathrm{g} / \mathrm{ml}$ nigericin, $3 \mathrm{mg} / \mathrm{ml}$ valinomycin, and either $10 \mathrm{mM}$ pyrazinoate, $87 \mathrm{mM}$ mannitol, $160 \mathrm{mM} \mathrm{K} \mathrm{K}^{+}, 2.5 \mathrm{mM}$ $\mathrm{MgSO}_{4}, 110 \mathrm{mM}$ phosphate, $20 \mathrm{mM}$ Hepes, pH $6.5(\bullet, \circ)$, or 10 $\mathrm{mM}$ gluconate, $62 \mathrm{mM}$ mannitol, $168 \mathrm{mM} \mathrm{K}^{+}, 3 \mathrm{mM} \mathrm{MgSO}_{4}, 117$ $\mathrm{mM}$ phosphate, $24 \mathrm{mM}$ Hepes, pH 6.5 ( $)$. Uptake of $7 \mu \mathrm{M}$ $\left[{ }^{14} \mathrm{C}\right]$ urate was then measured in the presence of $120 \mathrm{mM}$ mannitol, $165 \mathrm{mM} \mathrm{K}^{+}, 0.06 \mathrm{mM} \mathrm{MgSO}_{4}, 118 \mathrm{mM}$ phosphate, $0.5 \mathrm{mM}$ Hepes, pH 6.5, and either $0.2 \mathrm{mM}$ gluconate (๑), $0.2 \mathrm{mM}$ pyrazinoate (๑), or $0.2 \mathrm{mM}$ pyrazinoate and $2 \mathrm{mM}$ K-probenecid (o). coupled to urate entry. The rate of urate uptake in the presence of the outward pyrazinoate gradient was inhibited $>90 \%$ by 2 $\mathrm{mM}$ probenecid, which is consistent with the concept that urate-pyrazinoate exchange occurs via the previously described, probenecid-sensitive urate exchange system.

If urate-pyrazinoate exchange does occur via the same transport pathway that mediates urate- $\mathrm{OH}^{-}$exchange, then pyrazinoate- $\mathrm{OH}^{-}$exchange should also take place. To test this prediction, we measured the uptake of $29 \mu \mathrm{M}\left[{ }^{14} \mathrm{C}\right]$ pyrazinoate in the presence $\left(\mathrm{pH}_{0} 6.5 ; \mathrm{pH}_{\mathrm{i}} 7.5\right)$ or absence $\left(\mathrm{pH}_{\mathrm{o}} 7.5 ; \mathrm{pH}_{\mathrm{i}}\right.$ 7.5) of an outward $\mathrm{OH}^{-}$gradient (Fig. 2). This experiment was conducted in the presence of a valinomycin voltage clamp. As indicated in Fig. 2, imposing an outward $\mathrm{OH}^{-}$gradient stimulated the rate of pyrazinoate uptake and induced a transient overshoot above equilibrium, consistent with transport of pyrazinoate via exchange for $\mathrm{OH}^{-}$. Although not illustrated, the rate of pyrazinoate uptake in the presence of an outward $\mathrm{OH}^{-}$gradient was inhibited $>90 \%$ by $2 \mathrm{mM}$ probenecid, as expected if pyrazinoate- $\mathrm{OH}^{-}$exchange occurs via the urate exchange pathway.

If pyrazinoate- $\mathrm{OH}^{-}$exchange is mediated by the same transport system that catalyzes urate- $\mathrm{OH}^{-}$exchange, then $\mathrm{OH}^{-}$ gradient-stimulated pyrazinoate influx should be sensitive to inhibition by the same agents that inhibit $\mathrm{OH}^{-}$gradientstimulated urate influx. This prediction was tested in the experiments illustrated in Fig. 3. The rate of uptake of $24 \mu \mathrm{M}$ $\left[{ }^{14} \mathrm{C}\right]$ pyrazinoate (Fig. $3 \mathrm{~A}$ ) or $60 \mu \mathrm{M}\left[{ }^{14} \mathrm{C}\right]$ urate (Fig. $3 \mathrm{~B}$ ) was determined in the presence of an outward $\mathrm{OH}^{-}$gradient and varying concentrations of unlabeled pyrazinoate, urate, or nicotinate. For each of the three agents, the dose-response curve for inhibition of $\left[{ }^{14} \mathrm{C}\right]$ pyrazinoate uptake was similar to that for inhibition of $\left[{ }^{14} \mathrm{C}\right]$ urate uptake. For example, the concentration of urate causing $50 \%$ inhibition was just above $0.3 \mathrm{mM}$ for both the transport of $\left[{ }^{14} \mathrm{C}\right]$ pyrazinoate and the transport of $\left[{ }^{14} \mathrm{C}\right]$ urate. The concentration of nicotinate causing $50 \%$ inhibition was $0.1 \mathrm{mM}$ in both cases. Pyrazinoate was a slightly less potent inhibitor than nicotinate. These data provide further support for the concept that urate and pyrazinoate share the same transport system.

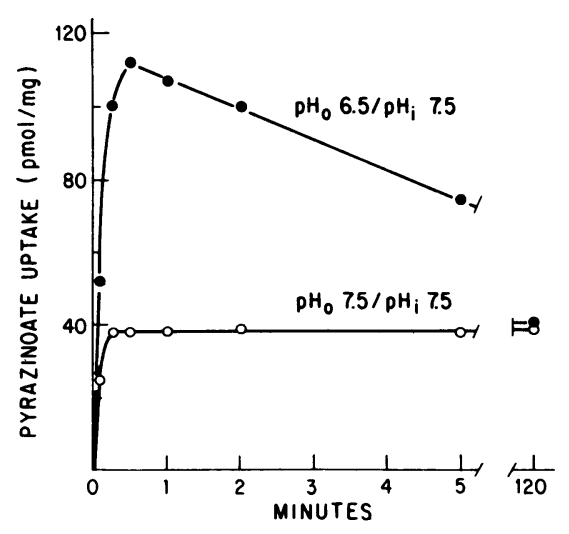

Figure 2. Stimulation of pyrazinoate uptake by an inside-alkaline pH gradient. Membrane vesicles were preincubated for $120 \mathrm{~min}$ in the presence of $3 \mathrm{mg} / \mathrm{ml}$ valinomycin, $100 \mathrm{mM}$ mannitol, $165 \mathrm{mM} \mathrm{K}^{+}$, $5 \mathrm{mM} \mathrm{MgSO}_{4}, 78 \mathrm{mM}$ phosphate, $40 \mathrm{mM}$ Hepes, pH 7.5. Uptake of $29 \mu \mathrm{M}\left[{ }^{14} \mathrm{C}\right]$ pyrazinoate was then measured in the presence of either $89 \mathrm{mM}$ mannitol, $165 \mathrm{mM} \mathrm{K}^{+}, 1 \mathrm{mM} \mathrm{MgSO}_{4}, 126 \mathrm{mM}$ phosphate, $8 \mathrm{mM}$ Hepes, pH $6.5(\bullet)$, or $159 \mathrm{mM}$ mannitol, $165 \mathrm{~K}^{+}, 1 \mathrm{mM}$ $\mathrm{MgSO}_{4}, 88 \mathrm{mM}$ phosphate, $8 \mathrm{mM}$ Hepes, pH 7.5 (o). 


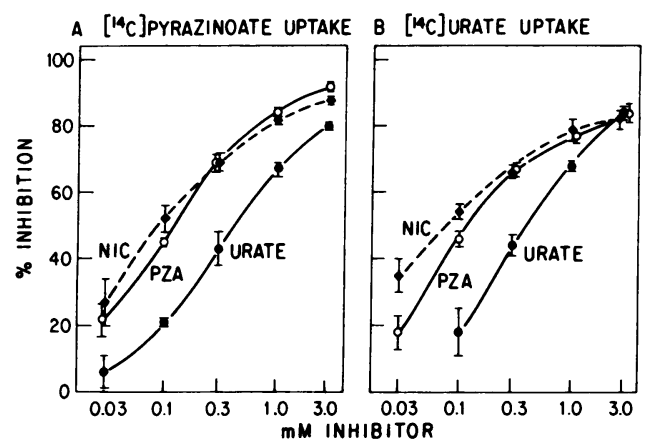

Figure 3. Effect of inhibitors on pH gradient-stimulated uptake of $\left[{ }^{14} \mathrm{C}\right]$ pyrazinoate and $\left[{ }^{14} \mathrm{C}\right]$ urate. The 2-s uptake of $24 \mu \mathrm{M}$ $\left[{ }^{14} \mathrm{C}\right]$ pyrazinoate $(A)$ and the 3-s uptake of $60 \mu \mathrm{M}\left[{ }^{14} \mathrm{C}\right]$ urate $(B)$ were assayed at external $\mathrm{pH} 6.5$ using vesicles preincubated at $\mathrm{pH} 7.5$ according to the protocol employed in Fig. 2. Inhibitors were added as $\mathrm{K}$ salts. Each datum represents the mean $\pm \mathrm{SE}$ for three separate experiments performed on different membrane preparations.

In rabbit renal microvillus membrane vesicles, $\mathrm{Na}^{+}$-nicotinate cotransport takes place and is inhibited by pyrazinoate but not by PAH (12). We therefore tested for the presence of $\mathrm{Na}^{+}$-pyrazinoate cotransport in dog microvillus membranes, as shown in Fig. 4. Imposing an inward $\mathrm{Na}^{+}$gradient accelerated the rate of uptake of $34 \mu \mathrm{M}\left[{ }^{14} \mathrm{C}\right]$ pyrazinoate, and caused a transient overshoot above equilibrium that was consistent with $\mathrm{Na}^{+}$-pyrazinoate cotransport.

$\mathrm{Na}^{+}$-lactate cotransport has been documented in microvillus membrane vesicles from rat (13), dog (8), and rabbit (14), and occurs via a pathway shared by many other monocarboxylic acid anions (14). This $\mathrm{Na}^{+}$-cotransport system is not shared by urate, inasmuch as $\mathrm{Na}^{+}$-lactate cotransport is not inhibited by urate (8), and the initial rate of urate uptake is not stimulated by $\mathrm{Na}^{+}$(7). If $\mathrm{Na}^{+}$-pyrazinoate cotransport takes place via the same pathway that mediates $\mathrm{Na}^{+}$-lactate cotransport, then $\mathrm{Na}^{+}$-stimulated pyrazinoate uptake should be sensitive to inhibition by the same substances that inhibit $\mathrm{Na}^{+}$stimulated lactate uptake. This prediction was tested in the experiments illustrated in Fig. 5. The rate of influx of $32 \mu \mathrm{M}$

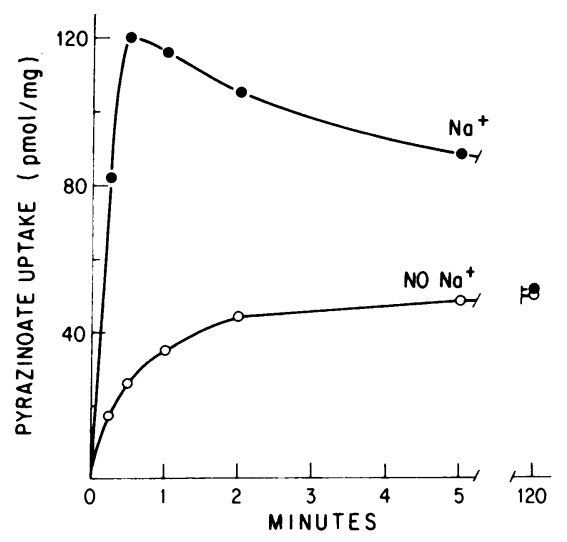

Figure 4. Stimulation of pyrazinoate uptake by an inward $\mathrm{Na}^{+}$ gradient. Membrane vesicles were prepared and suspended in 200 $\mathrm{mM}$ mannitol, $41 \mathrm{mM} \mathrm{K}{ }^{+}, 10 \mathrm{mM} \mathrm{MgSO}_{4}, 80 \mathrm{mM}$ Hepes, pH 7.5. Uptake of $34 \mu \mathrm{M}\left[{ }^{14} \mathrm{C}\right]$ pyrazinoate was then measured in the presence of $40 \mathrm{mM}$ mannitol, $8 \mathrm{mM} \mathrm{K}^{+}, 2 \mathrm{mM} \mathrm{MgSO}_{4}, 16 \mathrm{mM}$ Hepes, $\mathrm{pH} 7.5$, and either $140 \mathrm{mM}$ Na-gluconate (๑) or $140 \mathrm{mM} \mathrm{K}$-gluconate $(0)$.

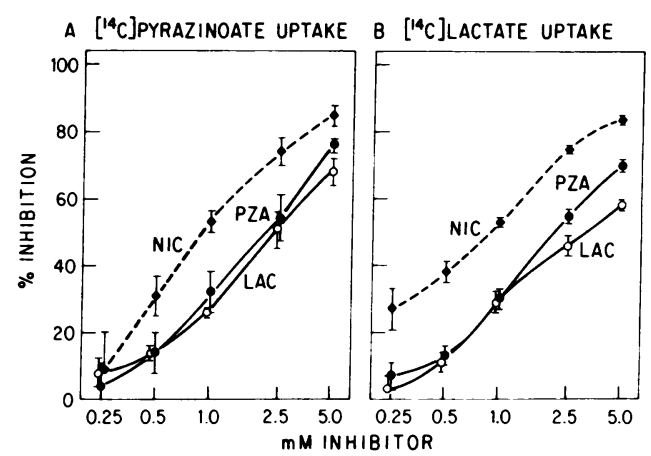

Figure 5. Effect of inhibitors on $\mathrm{Na}^{+}$gradient-stimulated uptake of $\left[{ }^{14} \mathrm{C}\right]$ pyrazinoate and $\left[{ }^{14} \mathrm{C}\right]$ lactate. The 2-s uptake of $32 \mu \mathrm{M}$ $\left[{ }^{14} \mathrm{C}\right]$ pyrazinoate $(A)$ and the 5-s uptake of $15 \mu \mathrm{M}\left[{ }^{14} \mathrm{C}\right]$ lactate $(B)$ were assayed in the presence of $140 \mathrm{mM} \mathrm{Na}^{+}$according to the protocol employed in Fig. 4. Inhibitors were added as Na salts. Each datum represents the mean \pm SE for three separate experiments performed on different membrane preparations.

$\left[{ }^{14} \mathrm{C}\right]$ pyrazinoate (Fig. $5 \mathrm{~A}$ ) or $15 \mu \mathrm{M}\left[{ }^{14} \mathrm{C}\right]$ lactate (Fig. $5 \mathrm{~B}$ ) was measured in the presence of an inward $\mathrm{Na}^{+}$gradient and varying concentrations of unlabeled pyrazinoate, lactate, or nicotinate. For each of the three agents, the dose-response curve for inhibition of $\left[{ }^{14} \mathrm{C}\right]$ pyrazinoate uptake was similar to that for inhibition of $\left[{ }^{14} \mathrm{C}\right]$ lactate uptake. For example, the concentration of nicotinate causing $50 \%$ inhibition was slightly under $1.0 \mathrm{mM}$ for both the transport of $\left[{ }^{14} \mathrm{C}\right]$ pyrazinoate and the transport of $\left[{ }^{14} \mathrm{C}\right]$ lactate. The concentration of lactate or pyrazinoate causing $50 \%$ inhibition was $\sim 2.5 \mathrm{mM}$ in both cases. At concentrations of $2.5 \mathrm{mM}$ and below, none of the three substances inhibited the $\mathrm{Na}^{+}$-stimulated uptake of 0.3 $\mu \mathrm{M}\left[{ }^{3} \mathrm{H}\right]$ glucose measured at $2 \mathrm{~s}$ under identical conditions (not shown), which argues against significant alterations in the electrochemical $\mathrm{Na}^{+}$gradient. Even at a concentration of 5 $\mathrm{mM}$, nicotinate, pyrazinoate, and lactate inhibited glucose uptake by only 1,15 , and $17 \%$, respectively. Thus, these data suggest that pyrazinoate and lactate share the same $\mathrm{Na}^{+}$ cotransport system in dog renal microvillus membranes.

We then attempted to demonstrate paradoxical effects of pyrazinoate and nicotinate on urate uptake in our membrane vesicle preparation. In Fig. 1, we showed that an outward pyrazinoate gradient could stimulate urate accumulation. In Fig. 4, we showed that an inward $\mathrm{Na}^{+}$gradient could induce the uphill accumulation of pyrazinoate. That is, an inward $\mathrm{Na}^{+}$gradient at least transiently could generate an outward pyrazinoate gradient. It therefore seemed possible that adding pyrazinoate to the external medium in the presence of an inward $\mathrm{Na}^{+}$gradient might stimulate urate accumulation. On the other hand, adding higher concentrations of pyrazinoate might reduce urate uptake as cis inhibition at the external face of the membrane became the predominant effect, as observed in Fig. 3. In the experiment illustrated in Fig. 6, the uptake of $48 \mu \mathrm{M}\left[{ }^{14} \mathrm{C}\right]$ urate was assayed in the presence of an inward $\mathrm{Na}^{+}$gradient with $0,0.1$, or $5 \mathrm{mM}$ pyrazinoate added to the external medium at the initiation of the uptake measurement. The lower dose of pyrazinoate stimulated the accumulation of urate and induced a transient overshoot. In contrast, the higher dose of pyrazinoate inhibited the rate of urate uptake.

Similar effects were noted with nicotinate (Fig. 7). Adding $0.04 \mathrm{mM}$ nicotinate to the external medium in the presence 


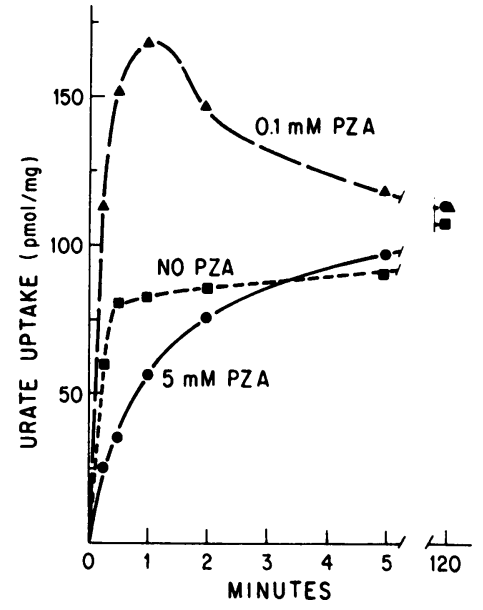

of an inward $\mathrm{Na}^{+}$gradient stimulated the accumulation of 65 $\mu \mathrm{M}\left[{ }^{14} \mathrm{C}\right]$ urate. However, adding $0.8 \mathrm{mM}$ nicotinate to the medium inhibited urate uptake. Neither $0.1 \mathrm{mM}$ pyrazinoate nor $0.04 \mathrm{mM}$ nicotinate affected urate uptake measured in the absence of an inward $\mathrm{Na}^{+}$gradient (not illustrated). Thus, paradoxical effects of drugs on urate absorption across the luminal membrane of dog proximal tubular cells were demonstrable in vitro.

\section{Discussion}

Our studies suggest that the paradoxical effects exerted on renal urate excretion by such drugs as pyrazinoate may arise from stimulation and inhibition of urate absorption across the luminal membrane of the proximal tubular cell, as schematically illustrated in Fig. 8. In the absence of pyrazinoate, urate absorption across the luminal membrane occurs in exchange for intracellular $\mathrm{OH}^{-}$(6) and several organic anions (8) for which a cell-to-lumen electrochemical gradient normally exists (process 1). If the concentrations of $\mathrm{OH}^{-}$and exchangeable organic anions within the cell are not saturating for the urate exchange process, then urate absorption across the luminal membrane will be stimulated when the concentration of exchangeable anions in the cell rises. Pyrazinoate, which can be accumulated within the cell by $\mathrm{Na}^{+}$-cotransport across the luminal membrane (process 2), can serve as an exchange partner for urate and thereby stimulate urate absorption (process 3). However, the higher the intratubular concentration of pyrazinoate, the more it will displace urate from the external

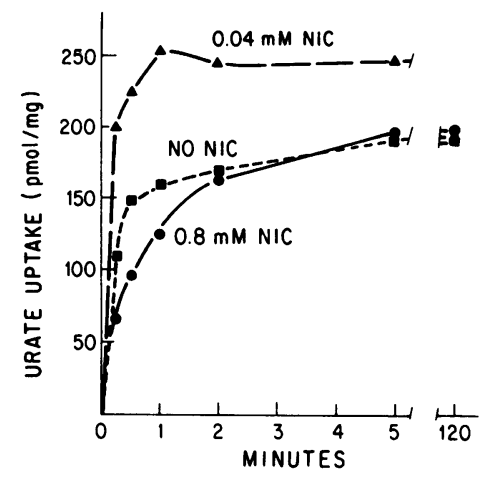

Figure 7. Paradoxical effects of nicotinate on urate uptake. Uptake of $65 \mu \mathrm{M}$ $\left[{ }^{14} \mathrm{C}\right]$ urate was assayed according to the protocol employed in Fig. 6 except that $0(\square), 0.04(\Delta)$, or $0.8 \mathrm{mM}$ (•) nicotinate rather than pyrazinoate was added to the experimental medium.

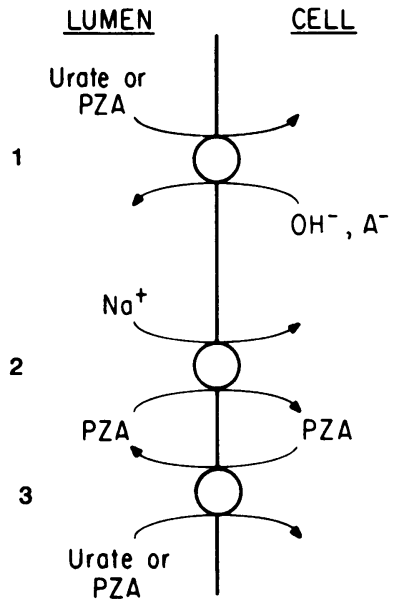

Figure 8. Schematic model to explain the paradoxical effects of pyrazinoate on urate transport across the luminal membrane of the proximal tubular cell. See text for details.

transport site of the anion exchanger. Ultimately, this cis inhibitory effect of pyrazinoate will predominate, and the rate of urate absorption will fall below the base-line rate measured in the absence of pyrazinoate.

Certainly, our studies do not rule out the possibility that drugs such as pyrazinoate may reduce urate excretion by inhibiting urate secretion across the basolateral membrane of the proximal tubular cell. However, the feasibility of the scheme we have proposed is underscored by the fact that the same pyrazinoate concentrations found to stimulate or inhibit absorption of urate across the luminal membrane in Fig. 6 actually cause urate retention or uricosuria, respectively, in the intact $\operatorname{dog}(4)$. In addition, species differences in the effects of pyrazinoate support the concept that the drug reduces urate excretion by stimulating urate absorption across the luminal membrane via anion exchange rather than by inhibiting urate secretion across the basolateral membrane. For example, pyrazinoate reduces urate excretion in the $\operatorname{dog}(2,4)$ and rat $(15)$, two species in which there is active, mediated urate reabsorption in the proximal tubule $(16,17)$ and in which urate transport via anion exchange has been demonstrated in renal microvillus membrane vesicles (6-9). In contrast, pyrazinoate does not reduce urate excretion in the rabbit (18). Rabbit proximal tubules secrete urate actively but have no mediated urate reabsorption $(19,20)$. Urate transport via anion exchange can not be demonstrated in rabbit renal microvillus membrane vesicles (8). In fact, pyrazinoate has not been found to reduce urate excretion in any animal-such as the pig (21), chicken (22), snake (23), or guinea pig (4)—in which the tubular transport of urate is in the direction of net secretion. A possible explanation for the inability of pyrazinoate to reduce urate excretion in animals that are net secretors of urate is that the luminal membranes of their proximal tubular cells may contain few or none of the anion exchangers whose principal function is to mediate active urate reabsorption.

In summary, we have demonstrated paradoxical effects of pyrazinoate and nicotinate on urate absorption into luminal membrane vesicles isolated from dog proximal tubular cells. These findings suggest that the paradoxical effect of uricosuric drugs at low doses to cause urate retention in vivo may result at least in part from stimulation of urate reabsorption and may not result simply from inhibition of urate secretion as commonly believed. 


\section{Acknowledgments}

The careful typing of the manuscript by Carol Robinson is gratefully acknowledged.

This work was supported by U. S. Public Health Service grants AM-17433 and AM-33793, and by an Established Investigatorship from the American Heart Association to Dr. Aronson.

\section{References}

1. Roch-Ramel, F., and I. M. Weiner. 1980. Renal excretion of urate: factors determining the actions of drugs. Kidney Int. 18:665676.

2. Weiner, I. M., and J. P. Tinker. 1972. Pharmacology of pyrazinamide: metabolic and renal function studies related to the mechanism of drug-induced urate retention. J. Pharmacol. Exp. Ther. 180:411-434.

3. Steele, T. H., and R. E. Rieselbach. 1967. The renal mechanism for urate homeostasis in man. Am. J. Med. 43:868-875.

4. Perez-Gonzales, M., and I. M. Weiner. 1983. Effects of pyrazinoate and p-aminohippurate on renal urate excretion by the dog and guinea pig. J. Pharmacol. Exp. Ther. 224:364-368.

5. Yü, T. F., and A. B. Gutman. 1959. Study of paradoxical effects of salicylate in low, intermediate and high dosage on the renal mechanisms for excretion of urate in man. J. Clin. Invest. 38:12981315.

6. Blomstedt, J. W., and P. S. Aronson. 1980. pH gradientstimulated transport of urate and para-aminohippurate in dog renal microvillus membrane vesicles. J. Clin. Invest. 65:931-934.

7. Kahn, A. M., and P. S. Aronson. 1983. Urate transport via anion exchange in dog renal microvillus membrane vesicles. Am. J. Physiol. 244:F56-F63.

8. Guggino, S. E., G. J. Martin, and P. S. Aronson. 1983. Specificity and modes of the anion exchanger in dog renal microvillus membranes. Am. J. Physiol. 244:F612-F621.

9. Kahn, A. M., S. Branham, and E. J. Weinman. 1983. Mechanism of urate and para-aminohippurate transport in rat microvillus membrane vesicles. Am. J. Physiol. 245:F151-F158.

10. Berge, K. G., R. W. P. Achor, N. A. Christensen, H. L. Mason, and N. W. Barker. 1961. Hypercholesterolemia and nicotinic acid: a long term study. Am. J. Med. 31:24-36.
11. Aronson, P. S., and B. Sacktor. 1975. The $\mathrm{Na}^{+}$gradientdependent transport of D-glucose in renal brush border membranes. J. Biol. Chem. 250:6032-6039.

12. Boumendil-Podevin, E. F., and R. A. Podevin. 1981. Nicotinic acid transport by brush border membrane vesicles from rabbit kidney. Am. J. Physiol. 240:F185-F191.

13. Barac-Nieto, M., H. Murer, and R. Kinne. 1980. Lactatesodium cotransport in rat renal brush border membranes. Am. J. Physiol. 239:F496-F506.

14. Nord, E. P., S. H. Wright, I. Kippen, and E. M. Wright. 1983. Specificity of the $\mathrm{Na}^{+}$-dependent monocarboxylic acid transport pathway in rabbit renal brush border membranes. J. Membrane Biol. 72:213221.

15. Abramson, R. G., and M. F. Levitt. 1976. Use of pyrazinamide to assess renal uric acid transport in the rat: a micropuncture study. Am. J. Physiol. 230:1276-1283.

16. Zins, G. R., and I. M. Weiner. 1968. Bidirectional urate transport limited to the proximal tubule in dogs. Am. J. Physiol. 215: 411-422.

17. Weinman, E. J., H. O. Senekjian, S. C. Sansom, D. Steplock, A. Sheth, and T. F. Knight. 1981. Evidence for active and passive urate transport in the rat proximal tubule. Am. J. Physiol. 240:F90F93.

18. Beechwood, E. C., W. O. Berndt, and G. H. Mudge. 1964. Stop-flow analysis of tubular transport of uric acid in rabbits. Am. J. Physiol. 207:1265-1272.

19. Shimomura, A., A. Chonko, R. Tanner, R. Edwards, and J. Grantham. 1981. Nature of urate transport in isolated rabbit proximal tubules. Am. J. Physiol. 241:F565-F578.

20. Senekjian, H. O., T. F. Knight, and E. J. Weinman. 1981. Urate transport by the isolated perfused $\mathrm{S}_{2}$ segment of the rabbit. $\mathrm{Am}$. J. Physiol. 240:F530-F535.

21. Simmonds, H. A., P. J. Hatfield, J. S. Cameron, and A. Cadenhead. 1976. Uric acid excretion by the pig kidney. Am. J. Physiol. 230:1654-1661.

22. Berger, L., T. F. Yü, and A. B. Gutman. 1960. Effect of drugs that alter uric acid excretion in man on uric acid clearance in chicken. Am. J. Physiol. 198:575-580.

23. Dantzler, W. H., and O. H. Brokl. 1984. Lack of effect of low $\left[\mathrm{Ca}^{2+}\right], \mathrm{La}^{3+}$, and pyrazinoate on urate transport by isolated, perfused snake renal tubules. Pfluegers Arch. 401:262-265. 